\title{
An acoustic gap between the NICU and womb: a potential risk for compromised neuroplasticity of the auditory system in preterm infants
}

\author{
Amir Lahav ${ }^{1,2 *}$ and Erika Skoe ${ }^{3}$ \\ ${ }^{1}$ Department of Pediatrics and Newborn Medicine, Brigham and Women's Hospital, Boston, MA, USA \\ 2 Department of Pediatrics, Harvard Medical School, MassGeneral Hospital for Children, Boston, MA, USA \\ ${ }^{3}$ Department of Speech, Language, and Hearing Sciences, Department of Psychology Affiliate, Cognitive Sciences Program Affiliate, University of Connecticut, \\ Storrs, CT, USA
}

Edited by:

Monica Munoz-Lopez, University of Castilla-La Mancha, Spain

Reviewed by:

Catherine J. Stevens, University of

Western Sydney, Australia

Karel Allegaert, Universitaire

Ziekenhuizen Leuven, Belgium

\section{*Correspondence:}

Amir Lahav, Department of

Pediatrics and Newborn Medicine,

Brigham and Women's Hospital, 75

Francis St. Boston, MA 02115, USA

e-mail:amir_lahav@hms.harvard.edu
The intrauterine environment allows the fetus to begin hearing low-frequency sounds in a protected fashion, ensuring initial optimal development of the peripheral and central auditory system. However, the auditory nursery provided by the womb vanishes once the preterm newborn enters the high-frequency (HF) noisy environment of the neonatal intensive care unit (NICU). The present article draws a concerning line between auditory system development and HF noise in the NICU, which we argue is not necessarily conducive to fostering this development. Overexposure to HF noise during critical periods disrupts the functional organization of auditory cortical circuits. As a result, we theorize that the ability to tune out noise and extract acoustic information in a noisy environment may be impaired, leading to increased risks for a variety of auditory, language, and attention disorders. Additionally, HF noise in the NICU often masks human speech sounds, further limiting quality exposure to linguistic stimuli. Understanding the impact of the sound environment on the developing auditory system is an important first step in meeting the developmental demands of preterm newborns undergoing intensive care.

Keywords: auditory development, NICU, preterm infants, noise exposure, high frequency

\section{AN ACOUSTIC GAP BETWEEN THE NICU AND THE WOMB}

Surrounded by amniotic fluid, the first sounds the fetus experiences are low-frequency digestive noises and maternal sounds transmitted through the bones of the skull (Querleu et al., 1988; Lecanuet and Schaal, 1996; Sohmer et al., 2001). However, preterm infants (born $<37$ weeks of gestation) are no longer surrounded by fluids or live underwater, and this new reality forces them to hear primarily through air conduction despite their auditory system being accustomed to bone conduction. This major difference in the primary mode of hearing (bone vs. air conduction) and the medium of sound transmission (fluid vs. air), presents an acoustic gap between the unnatural acoustic environment of the hospital and the developmental demands of the newborn's auditory system. The developmental implications of this acoustic gap remain largely unstudied. Differences between the auditory environments in the neonatal intensive care unit (NICU) vs. the womb are summarized in Table 1. Unlike the womb, the primary auditory stimulation available to intensive care neonates is environmental noise generated by ventilators, infusion pumps, fans, telephones, pagers, monitors, and alarms. Such excessive exposure to high-frequency noise, and recurrent electronic beeps that would not otherwise be present had the baby remained protected by the intrauterine environment and not been born prematurely, constitutes a trauma to the auditory system of a preterm infant. This acoustic trauma, we argue, may be potentially harmful, increasing the risk for auditory, language, and attention disorders. Although cases of hearing disorders in newborns are typically associated with congenital malformations, prenatal infections, and drug exposure (for review see Resendes et al., 2001; Beswick et al., 2012), this article is specifically focused on auditory impairments induced by environmental noise.

While exposure to loud noise is intuitively understood to be distracting and harmful, the shortage of biological and periodic auditory stimuli in the NICU environment is less acknowledged to be of concern. For example, the sensory perception of the maternal heartbeat in the womb provides the fetus with an important rhythmic experience that likely explains the natural tendency of the newborn to seek auditory entrainment soon after birth (Ingersoll and Thoman, 1994; Ullal-Gupta et al., 2013). In contrast, the more random, aperiodic nature of NICU noise suppresses opportunities for rhythmic entrainment known to facilitate arousal regulation (Smith and Steinschneider, 1975) and social interactions (Phillips-Silver et al., 2010) in early infancy.

\section{THE FREQUENCY SPECTRA IN THE NICU vs. THE WOMB: IMPLICATIONS FOR THE TONOTOPIC DEVELOPMENT OF THE AUDITORY SYSTEM}

Auditory development is a slow process that begins in utero. Critical aspects of this development take place before full 
Table 1 | An acoustic gap between the NICU and the womb environments.

\begin{tabular}{|c|c|c|}
\hline & Womb & NICU \\
\hline Primary mode of hearing & Bone conduction & Air conduction \\
\hline Sound transmission medium & Fluid & Air \\
\hline Sound attenuation & $\begin{array}{l}\text { Attenuation provided by maternal tissue and } \\
\text { fluids }\end{array}$ & Direct exposure to sound source \\
\hline Frequency range of sound exposure & Primarily low frequency $(<500 \mathrm{~Hz})$ & Broad spectrum \\
\hline Ambient noise dosage & Restricted daily exposure to noise & $\begin{array}{l}\text { Excessive daily exposure to noise (e.g., alarms, } \\
\text { white noise, and multi-talker babble) }\end{array}$ \\
\hline Most prevalent sounds in environment & $\begin{array}{l}\text { Maternal vocalizations, biological sounds (e.g., } \\
\text { heartbeat, digestive noises) }\end{array}$ & Electronic, unnatural, non-biological sounds \\
\hline Exposure to language & High-quality stimuli, primarily from mother & $\begin{array}{l}\text { Poor quality stimuli during non-visiting hours, } \\
\text { primarily from multi-talker babble }\end{array}$ \\
\hline Complexity of prevalent sounds in environment & $\begin{array}{l}\text { Rhythmic, periodic, organized, predictable } \\
\text { (e.g., heartbeat) }\end{array}$ & $\begin{array}{l}\text { Aperiodic (e.g., white noise), unorganized, } \\
\text { unpredictable (e.g., alarms) }\end{array}$ \\
\hline
\end{tabular}

gestation and are therefore vulnerable to disruption by the NICU environment especially given that the frequency spectrum of the NICU environment is quite different from what is experienced in the womb. Previous studies have shown that the acoustic environment of the NICU contains a significant amount of HF noise $(>500 \mathrm{~Hz})$, emanating from a wide variety of medical equipment and human activity that are unlikely to be heard in the womb (Kellam and Bhatia, 2008; Livera et al., 2008). A recent study using sound spectral analysis over a five-day period showed that NICU infants were exposed to frequencies between 500 and $16,000 \mathrm{~Hz} 57 \%$ of the time, with the majority of exposure being during daytime falling in the range of $501-3150 \mathrm{~Hz}$ (Lahav, 2014). The potential risk of HF noise exposure in the NICU is further increased by the fact that the frequency spectra of NICU noise is rarely monitored, with majority of studies in the field solely focused on measuring loudness levels.

High-frequency frequency noise exposure in the NICU is a concern because the auditory system is still functionally underdeveloped at birth, with critical stages of development occurring during the final weeks of gestation (for review, see Graven and Browne, 2008). While the structural components of the inner ear (bony labyrinth of the cochlea) are already formed by 15 weeks gestational age (GA), the onset of cochlear function does not occur until 24 weeks GA or later (Pujol et al., 1991; Moore and Linthicum, 2007). As evidence of the functional onset of hearing, electrophysiological data from preterm neonates demonstrates that brainstem auditory evoked potentials are first recordable between 25 and 32 weeks GA (Starr et al., 1977; Amin et al., 2003; Yin et al., 2008; Coenraad et al., 2011; Jiang and Chen, 2014). After 34 weeks GA once the spiral ganglion neurons in the cochlea have formed sufficient neural connections with the auditory brainstem and have begun to extend those connections toward the auditory cortex, evoked potentials to sound become more robust (Pujol and Lavigne-Rebillard, 1992; Hepper and Shahidullah, 1994; Hall, 2000).

Development of the cochlea and central auditory system is complex. Within the cochlea, reside tens of thousands of inner hair cells, sensory receptors, that each respond maximally to a specific frequency (Pujol et al., 1991; Pujol and Lavigne-Rebillard, 1992; Morlet et al., 1993). These hair cells are arranged tonotopically with high-frequency hair cells located basally (closer to the middle ear) and low-frequency ones located apically (Kandler et al., 2009) (see Figure 1). This cochlear tonotopy is preserved along the auditory neuroaxis as a consequence of spiral ganglion neurons establishing precise connections between cochlear hair cells and target neurons in the auditory brainstem that code for different sound frequencies (Pujol and Lavigne-Rebillard, 1992; Appler and Goodrich, 2011). Gradual development of these tonotopic frequency maps occurs with low-frequency regions maturing before high-frequency ones, a process often referred to as "frequency-dependent plasticity" (Talavage et al., 2000). This low-to-high developmental gradient is promoted by the acoustic makeup of the womb in which frequencies above $500 \mathrm{~Hz}$ are attenuated by maternal tissues and fluids within the intrauterine cavity. Toward the end of pregnancy, as the walls of the uterine lining begin to thin, gradually more HF energy $(>500 \mathrm{~Hz})$ is passed through the womb (Bench, 1968; Gerhardt, 1989; Gerhardt et al., 1990; Hepper and Shahidullah, 1994; Abrams and Gerhardt, 2000). Thus, while the womb provides an optimal medium for the initial phases of hearing development by limiting exposure to HF sounds (Hall, 2000), the sound frequencies present in the NICU are not necessarily conducive to furthering this development (Graven, 2000) (see Figure 1). Increased exposure to HF stimulation in the NICU while a majority of cochlear neurons are still migrating (Battin et al., 1998; Bystron et al., 2008) and cortical folding is still in flux, may disrupt the normal tonotopic tuning of cochlear hair cells, and hinder auditory development subcortically and cortically (Walker et al., 1971). Thus, owing to the experience-dependent nature of auditory development (Zhang et al., 2001; Chang and Merzenich, 2003; Oliver et al., 2011; Zhou et al., 2011), the statistical properties of the acoustic environment in the NICU may potentially misguide the topographic assembly of the auditory brain system (Pujol and Lavigne-Rebillard, 1992), resulting in poorer frequency resolution. It is therefore likely that overexposure to HF noise during this critical period may impede the developing auditory system with effects seen well-beyond the postnatal period. 


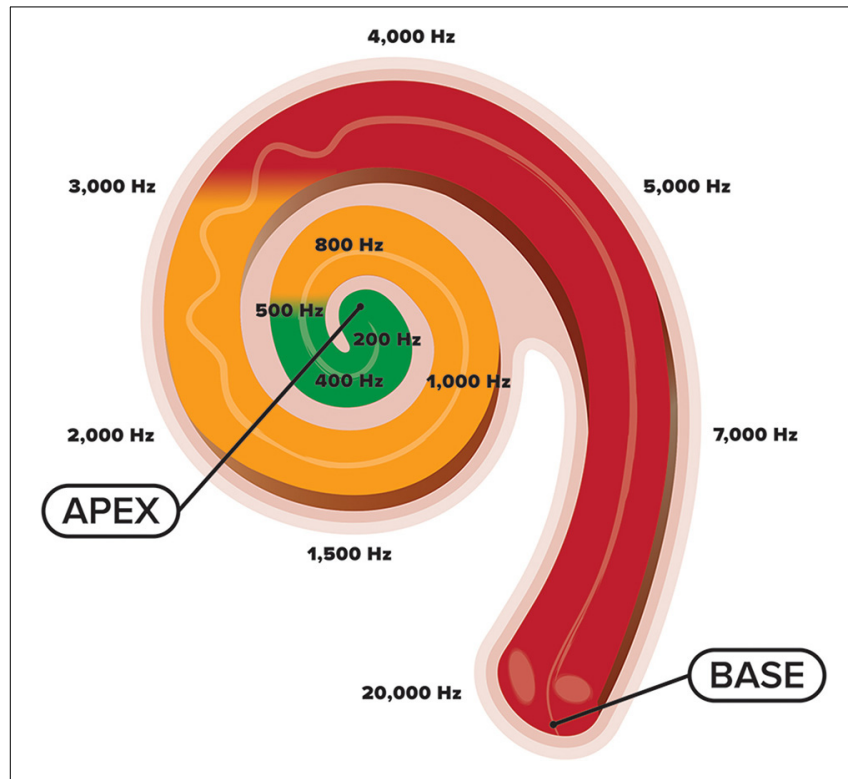

FIGURE 1 | An illustration of the cochlea and its tonotopic development across the frequency spectrum. High-frequency sounds maximally stimulate the base of the cochlea, whereas low-frequency sounds maximally stimulate the apex. Whereas the fetus is primarily exposed to sound frequencies below $500 \mathrm{~Hz}$ (green shade), preterm newborns are exposed to the entire frequency spectrum (green, orange, and red shades), coming from various electronic sounds in the NICU environment.

\section{CAN THE FETUS HEAR HF SOUNDS ORIGINATING OUTSIDE OF THE WOMB?}

As a consequence of the acoustic properties of the womb, the fetus receives, for the most part, a low-pass filtered version of the auditory environment in the world. Given the low-to-high frequency development of the cochlea, this raises the question of whether the fetus can in fact hear HF sounds that are loud enough to penetrate the womb and, if yes, when does this responsivity to HF sounds emerge? These questions have been addressed directly and indirectly by several studies using a variety of techniques. Hepper and Shahidullah (1994) examined the responsiveness of the human fetus to external auditory stimuli (pure tones) presented by a loudspeaker placed on the maternal abdomen at different frequencies $(100,250,500,1000$, and $3000 \mathrm{~Hz})$. Recording of fetal movements via ultrasound revealed a preferential sensitivity of the fetus to external sounds in the low-frequency range $(<500 \mathrm{~Hz})$ as early as 19 weeks of gestation. At 27 weeks GA, the vast majority of fetuses responded to sounds below $500 \mathrm{~Hz}$ but none responded to the higher frequency sounds at $1000 \mathrm{~Hz}$ or $3000 \mathrm{~Hz}$. Responsiveness to sounds above $1000 \mathrm{~Hz}$ was not observed until 33 weeks gestation. For all frequencies presented, there was a significant decrease in the intensity required to elicit a response with increased GA, likely due to the maturation of the auditory system and the thinning of the intrauterine walls in the last trimester of the pregnancy (Querleu et al., 1988). A followup study by Kisilevsky et al. (2000) using high volume high-pass filtered white noise $(800-20,000 \mathrm{~Hz})$ presented to the mother's abdomen showed that sound-evoked responses (in the form of cardiac acceleration and body movement) emerged at 30 weeks for both low-risk and high-risk fetuses, and required less intense stimulation to evoke responses later in development. While both studies indicate that sensitivity to HF sound emerges during the 7-8th month of gestation, neither study examined auditory system function directly but instead used fetal movements as an indirect measurement of hearing sensitivity.

Studies using MEG- and fMRI-based techniques in fetuses provide more direct measurement of auditory cortical function to HF sounds presented at high intensity. This body of research has provided modest evidence that the auditory cortex is activated by frequencies above $500 \mathrm{~Hz}$ by 33 weeks (Draganova et al., 2005; Jardri et al., 2008), that by 33-36 weeks that the fetus can differentiate a $500 \mathrm{~Hz}$ sound from a higher frequency one (Draganova et al., 2005), and that later in gestation (37-41 weeks) the auditory cortex is activated by naturalistic sounds containing a broad spectrum of frequencies (Moore et al., 2001). Thus, the likelihood exists that by $\sim 33$ weeks, there is a degree of HF penetration of external sounds through the abdomen, allowing the fetal auditory system to be activated by the high-frequency aspects of speech and other complex, naturalistic stimulation. This prenatal exposure to HF naturalistic sounds has been argued to prime the fetus for voice recognition, vowel discrimination, melody discrimination, among other complex auditory skills (reviewed in Granier-Deferre et al., 2011).

Based on the studies reviewed in this section, it appears that fetuses can respond to HF sounds transmitted through the maternal abdomen after $\sim 33$ weeks, and that responsiveness increases with GA. However, the mere fact that fetuses are capable of responding to HF noise does not necessarily imply they should be exposed to such sounds, especially in high doses. The existing literature does not rule out the possibility that the intense exposure to HF sounds used in these specific experiments, especially during early stages of development, was in fact harmful. Therefore, the potential harm of intense, direct, and repeated exposure to HF noise without the protection of the maternal abdomen, as experienced by extremely preterm infants in the NICU, should be given a more carefully evaluation. However, unlike HF noise, exposure to potentially positive HF sounds (e.g., speech, music) during the last stages of gestation may in fact help set the stage for hearing and language skills.

\section{NOISE-INDUCED PLASTICITY IN THE AUDITORY SYSTEM FUNCTION}

Our concern regarding the adverse effects of HF noise exposure is supported by evidence from animal studies. Animal models have revealed that sensory impoverishment during critical periods of development, in the form of acoustic noise or reduced complexity of auditory input, can lead to malformed tonotopic cortical maps, reduced neural synchrony, and broader tuning curves, which reflect decreased frequency-sensitivity of the auditory system (Zhang et al., 2001, 2002; Oliver et al., 2011). For example, young rats repeatedly exposed to HF tone pips showed distorted auditory function later in life (Oliver et al., 2011). The residual effects of that early augmented environment included altered brainstem auditory evoked potentials to the frequency of overstimulation, in addition to expanded neural frequency maps (Oliver et al., 2011). As a consequence of this early unnatural 
sound experience, the rat's auditory system became tuned to the frequency of the tone pips at the expense of processing other sound frequencies. Modification of tonotopic maps in deaf individuals (Guiraud et al., 2007) and musicians (Pantev et al., 1998), suggests that similar experience-dependent developmental principles operate in humans. It is therefore likely that the abrupt transition from the womb to the NICU changes the typical patterns of auditory development, specifically altering how frequency information is processed and coded.

In addition to compromising tonotopy, increased HF noise exposure during the neonatal period may have other long-term consequences for the functional integrity of the auditory system. In recent years, there has been growing concern about environmental noise in individuals of all ages. Indeed, sound intensities once thought to be safe for the auditory system are now considered less safe, especially for more extended exposures (Maison et al., 2013; Basner et al., 2014; Gourevitch et al., 2014). In laboratory animals, prolonged noise exposure has been shown to impede auditory development (Chang and Merzenich, 2003), accelerate age-related hearing losses (Kujawa and Liberman, 2006), increase neural loss (Salthouse and Lichty, 1985; Maison et al., 2013), and reduce neural efficiency by increasing the spontaneous firing of auditory neurons in the absence of sound stimulation (Costalupes et al., 1984; Seki and Eggermont, 2003). Moreover, in children, excessive noise exposure can manifest in decreased reading and cognitive performance (Cohen et al., 1973; Bronzaft and McCarthy, 1975; Hygge et al., 2003), and may change how children discriminate and attend to auditory stimuli (Cohen et al., 1973; Evans and Kantrowitz, 2002; Evans et al., 2009), even when tested in quiet environments.

Considering the acoustic gap between the NICU environment and the womb, it is not surprising that auditory development is compromised in preterm compared to full-term newborns. Studies using brainstem auditory evoked potentials suggest that preterm infants have delayed myelination of the central auditory pathway (Pasman et al., 1996; Roopakala et al., 2011; Hasani and Jafari, 2013) in addition to atypical neural pathways when processing, discriminating, and memorizing auditory information (Fellman et al., 2004; Therien et al., 2004). Thus, exposing preterm infants to HF noise too early, while the auditory system is still immature, may hinder the normal development of hearing and subsequent language acquisition.

\section{INCREASED BEHAVIORAL RELEVANCE OF HF NOISE AS A CONSEOUENCE OF NICU EXPERIENCE}

In addition to the presumably harmful effects of HF noise exposure to auditory system development, the collection of electronic noises in the NICU environment (coming from ventilators, telephones, pagers, and alarms) can often produce sufficient acoustic energy to mask natural human speech sounds potentially important to the preterm infant, whose exposure to linguistic stimuli is already restricted. This impoverished linguistic experience increases the behavioral relevance of noise, by shifting attentional focus away from speech sounds toward the noise in the environment. Behavioral and neurophysiological data from fetuses and healthy newborns, have revealed that fetuses become sensitive to sounds in the environment that are transmitted through the amniotic fluid including the sound of the mother's and father's voices (Fifer and Moon, 1994; Kisilevsky et al., 2003; Beauchemin et al., 2011; Voegtline et al., 2013; Lee and Kisilevsky, 2014) (reviewed in, Fava et al., 2011), with evidence of experiencedependent auditory learning emerging before birth (Kujala et al., 2003; Partanen et al., 2013; Krueger and Garvan, 2014). Given the importance of early experience in molding the auditory system (Skoe and Chandrasekaran, 2014), increased exposure to noise may over sensitize infants to noise, and, as a consequence, neural circuits may be formed to make noise the primary target of attention rather than treating it as a background stimulus that should be ignored. While this is an intriguing possibility, further research is needed to confirm or dispute this hypothesis.

Another factor that may impede the preterm infant's ability to tune out noise, is the immaturity of auditory feedback mechanisms (Morlet et al., 1993; Graven and Browne, 2008). In addition to inner hair cells, the cochlea contains outer hair cells that receive feedback from the central auditory system that buffer noise-induced damage and improve speech intelligibility in noise (Guinan, 2006). Background noise leads to a decrease in speech intelligibility that poses a perceptual challenge even for healthy adults with normal hearing. In addition to masking the signal due to physical overlap between the acoustics of noise and the acoustics of speech, noise acts as a competing signal that interferes with the ability to attend to a concurrent speech stream (Assmann and Summerfield, 1999). If greater behavioral relevance (i.e., unconscious attention) is placed on noise in the environment, or if biological feedback mechanisms are not fully intact, this could create further challenges for processing speech in noise for the preterm infant both in the immediate and also later in life. In support of this possibility, studies using brainstem auditory evoked potentials suggest that preterm infants have delayed myelination of the central auditory pathways (Pasman et al., 1996; Roopakala et al., 2011), which is associated with a variety auditory processing disorders (APD). Whether or not the high prevalence of APD in preterm population is attributed to the presence of highfrequency noise in the NICU is undetermined. However, one of the hallmarks of APD is difficulty processing target signals within a background of noise (Keith, 1999), further supporting the possibility that exposure to HF noise of the NICU environment may impede the preterm infant's ability to pull out signals from noise.

\section{OPTIMAL FREOUENCY EXPOSURE FOR INTENSIVE CARE NEONATES: LACK OF RECOMMENDED STANDARDS}

Current guidelines set by the American Academy of Pediatrics (AAP) are primarily focused on loudness levels, leaving the potential risks of HF noise exposure in the NICU infants largely unaddressed. According to AAP standards (White et al., 2013), the combination of continuous background sound and operational sound shall not exceed an hourly Leq of $45 \mathrm{~dB}$ and an hourly L10 of $50 \mathrm{~dB}$, while transient sounds (Lmax) shall not exceed $65 \mathrm{~dB}$, all A-weighted slow response measurements (White et al., 2013). However, in practice, previous studies examining noise in the NICU have reported extremely high noise levels, exceeding the AAP recommended standards more than $70 \%$ of the time (Williams et al., 2007). Sound measurements within the NICU environment have been measured between 62 and $70 \mathrm{dBA}$ 
(Philbin and Gray, 2002), with peak impulses exceeding $90 \mathrm{dBA}$ (Williams et al., 2007) and 120 dBA (Kent et al., 2002). In another study, sound measurements yielded an overall average hourly level (Leq) of approximately $60 \mathrm{dBA}$ with peak levels (Lmax) of 78.39 dBA (Krueger et al., 2005).

The problem of loud noise in the NICU has been diminished by modifications to NICU architectural designs, as more hospitals transition toward the single-room model in which newborns are housed in private rooms vs. the open-bay model where multiple babies are co-cared in a large room (White, 2011). Studies have shown that private-room NICUs are generally quieter than openbay NICUs (Szymczak and Shellhaas, 2014), except when highfrequency ventilation is used (Liu, 2012). However, while private rooms may have more favorable acoustics than open-bay designs, care should still be taken to ensure that the peak intensity and frequency characteristics in the NICU environment, even within a private room, are still optimal for preterm newborns. Thus, in the absence of clear guidelines and recommendations regarding the acoustic makeup of optimal sound exposure at birth, the NICU may present an acoustic danger zone for preterm newborns.

\section{LIFELONG AUDITORY PLASTICITY: RECOVERY OPTIONS FOR PRETERM INFANTS}

While experience-dependent plasticity is greatest in the early years, the auditory system maintains the potential for malleability throughout life (Sanes and Woolley, 2011). For example, auditory brain plasticity has been demonstrated in older adults following short-term sound-based training (Tremblay et al., 2001; Song et al., 2008; Anderson et al., 2013). Similarly, musical training has been shown improve linguistic and cognitive abilities (Moreno et al., 2009; Strait et al., 2014) and speech intelligibility in noise (Strait et al., 2012) in young children, leading to neural enhancements of brain structure and function (Hyde et al., 2009; Halwani et al., 2011; Ellis et al., 2012; Strait and Kraus, 2014), and buffering against auditory aging in older adults (Parbery-Clark et al., 2009, 2012). In addition, cochlear implants can induce functional plasticity in the auditory brainstem even after many years of deafness in childhood, demonstrating the high degree of modifiability in brain mechanisms that support hearing abilities (Gordon et al., 2011; Cardon et al., 2012). Thus, our auditory histories—whether in the form of excessive noise, acoustic deprivation, or augmented sound training — can influence auditory processes across the lifespan (Skoe and Chandrasekaran, 2014).

What are the implications of this lifelong plasticity for preterm infants following NICU discharge? While the NICU environment may initially compromise the auditory development, it is encouraging that the post-NICU environment may help to close the developmental gap by allowing for near normal to normal auditory functionality later in life. Enriched home literacy environment and quality exposure to auditory and linguistic stimuli in the post-NICU environment are considered fundamental building blocks for this auditory neuroplasticity, laying the foundation for speech and language development (Burgess et al., 2002; Roberts et al., 2005; Rowe and Goldin-Meadow, 2009; Hart and Risley, 2010; Hammer et al., 2010; Skoe et al., 2013; RamirezEsparza et al., 2014). Although hearing, language, and attention deficits are common among preterm infants (Vohr, 2014), the fact that some children born prematurely manage to catch up to their peers suggests that despite the initial auditory trauma induced by the NICU environment, the window of opportunities for further plasticity and recovery remains open.

\section{CONCLUSIONS}

The acoustic gap between the NICU and the womb, although somewhat unescapable, poses a hazard that may disrupt auditory development in intensive care neonates. As a consequence of the NICU environment, preterm infants receive a heavier dose of HF noise than what would be normally possible in the womb. The long-term effects of HF noise exposure on the development of preterm newborns prior to full gestation development is a growing area of research of particular clinical importance. The negative plasticity of the auditory brain system in response to HF noise exposure is concerning and highlights the importance of the newborn's sensory experience during postnatal hospitalization. It is tempting to theorize that excessive exposure to high-frequency noise during critical periods may be a contributing factor to the language, attention, and cognitive deficits often seen in the preterm population. Despite these evident concerns regarding HF noise exposure, current guidelines set by the AAP (White et al., 2013) are primarily focused on loudness levels, leaving the potential risks of HF noise exposure in the NICU largely overlooked. More knowledge of the spectral content of NICU noise would help in evaluating the auditory developmental consequences in NICU graduates. Intensive care neonates deserve to have a better protection plan against toxic sounds.

\section{ACKNOWLEDGMENTS}

We gratefully thank Linda Malie for assisting with graphic design of Figure 1 and Parker Tichko for comments on the manuscript. We are also grateful for the generous support Amir Lahav received from the Charles H. Hood Foundation, Peter and Elizabeth C. Tower Foundation, Gerber Foundation, Little Giraffe Foundation, Hailey's Hope Foundation, Jackson L. Graves Foundation, and TripAdvisor Fund.

\section{REFERENCES}

Abrams, R. M., and Gerhardt, K. J. (2000). The acoustic environment and physiological responses of the fetus. J. Perinatol. 20, S31-S36. doi: 10.1038/sj.jp.7200445

Amin, S. B., Orlando, M. S., Dalzell, L. E., Merle, K. S., and Guillet, R. (2003). Brainstem maturation after antenatal steroids exposure in premature infants as evaluated by auditory brainstem-evoked response. J. Perinatol. 23, 307-311. doi: 10.1038/sj.jp.7210898

Anderson, S., White-Schwoch, T., Parbery-Clark, A., and Kraus, N. (2013). Reversal of age-related neural timing delays with training. Proc. Natl. Acad. Sci. U.S.A. 110, 4357-4362. doi: 10.1073/pnas.1213555110

Appler, J. M., and Goodrich, L. V. (2011). Connecting the ear to the brain: Molecular mechanisms of auditory circuit assembly. Prog. Neurobiol. 93, 488-508. doi: 10.1016/j.pneurobio.2011.01.004

Assmann, P., and Summerfield, Q. (1999). The perception of speech under adverse conditions. Speech processing in the auditory system. Springer Handb. Aud. Res. 18, 231-308.

Basner, M., Babisch, W., Davis, A., Brink, M., Clark, C., Janssen, S., et al. (2014). Auditory and non-auditory effects of noise on health. Lancet 383, 1325-1332. doi: 10.1016/S0140-6736(13)61613-X

Battin, M. R., Maalouf, E. F., Counsell, S. J., Herlihy, A. H., Rutherford, M. A., Azzopardi, D., et al. (1998). Magnetic resonance imaging of the brain in very preterm infants: visualization of the germinal matrix, early myelination, and cortical folding. Pediatrics 101, 957-962. doi: 10.1542/peds.101.6.957 
Beauchemin, M., Gonzalez-Frankenberger, B., Tremblay, J., Vannasing, P., Martinez-Montes, E., Belin, P., et al. (2011). Mother and stranger: an electrophysiological study of voice processing in newborns. Cereb. Cortex 21, 1705-1711. doi: 10.1093/cercor/bhq242

Bench, J. (1968). Sound transmission to the human foetus through the maternal abdominal wall. J. Genet. Psychol. 113, 85-87. doi: 10.1080/00221325.1968.10533811

Beswick, R., Driscoll, C., and Kei, J. (2012). Monitoring for postnatal hearing loss using risk factors: a systematic literature review. Ear Hear. 33, 745-756. doi: 10.1097/AUD.0b013e31825blcd9

Bronzaft, A. L., and McCarthy, D. P. (1975). The effect of elevated train noise on reading ability. Environ. Behav. 7, 517-528. doi: 10.1177/001391657500700406

Burgess, S. R., Hecht, S. A., and Lonigan, C. J. (2002). Relations of the home literacy environment (HLE) to the development of reading-related abilities: a one-year longitudinal study. Read. Res. Q. 37, 408-426. doi: 10.1598/RRQ.37.4.4

Bystron, I., Blakemore, C., and Rakic, P. (2008). Development of the human cerebral cortex: Boulder Committee revisited. Nat. Rev. Neurosci. 9, 110-122. doi: $10.1038 / \mathrm{nrn} 2252$

Cardon, G., Campbell, J., and Sharma, A. (2012). Plasticity in the developing auditory cortex: evidence from children with sensorineural hearing loss and auditory neuropathy spectrum disorder. J. Am. Acad. Audiol. 23, 396-411. quiz: 95. doi: 10.3766/jaaa.23.6.3

Chang, E. F., and Merzenich, M. M. (2003). Environmental noise retards auditory cortical development. Science 300, 498-502. doi: 10.1126/science. 1082163

Coenraad, S., Toll, M. S., Hoeve, H. L., and Goedegebure, A. (2011). Auditory brainstem response morphology and analysis in very preterm neonatal intensive care unit infants. Laryngoscope 121, 2245-2249. doi: 10.1002/lary.22140

Cohen, S., Glass, D. C., and Singer, J. E. (1973). Apartment noise, auditory discrimination, and reading ability in children. J. Exp. Soc. Psychol. 9, 407-422. doi: 10.1016/S0022-1031(73)80005-8

Costalupes, J. A., Young, E. D., and Gibson, D. J. (1984). Effects of continuous noise backgrounds on rate response of auditory nerve fibers in cat. J. Neurophysiol. 51, 1326-1344.

Draganova, R., Eswaran, H., Murphy, P., Huotilainen, M., Lowery, C., and Preissl, H. (2005). Sound frequency change detection in fetuses and newborns, a magnetoencephalographic study. Neuroimage 28, 354-361. doi: 10.1016/j.neuroimage.2005.06.011

Ellis, R. J., Norton, A. C., Overy, K., Winner, E., Alsop, D. C., and Schlaug, G. (2012). Differentiating maturational and training influences on fMRI activation during music processing. Neuroimage 60, 1902-1912. doi: 10.1016/j.neuroimage.2012.01.138

Evans, G. W., and Kantrowitz, E. (2002). Socioeconomic status and health: the potential role of environmental risk exposure. Annu. Rev. Public Health 23, 303-331. doi: 10.1146/annurev.publhealth.23.112001.112349

Evans, J. L., Saffran, J. R., and Robe-Torres, K. (2009). Statistical learning in children with specific language impairment. J. Speech Lang. Hear. Res. 52, 321-335. doi: 10.1044/1092-4388(2009/07-0189)

Fava, E., Hull, R., and Bortfeld, H. (2011). Linking behavioral and neurophysiological indicators of perceptual tuning to language. Front. Psychol. 2:174. doi: 10.3389/fpsyg.2011.00174

Fellman, V., Kushnerenko, E., Mikkola, K., Ceponiene, R., Leipala, J., and Naatanen, R. (2004). Atypical auditory event-related potentials in preterm infants during the first year of life: a possible sign of cognitive dysfunction? Pediatr. Res. 56, 291-297. doi: 10.1203/01.PDR.0000132750.97066.B9

Fifer, W. P., and Moon, C. M. (1994). The role of mother's voice in the organization of brain function in the newborn. Acta Paediatr. Suppl. 397, 86-93. doi: 10.1111/j.1651-2227.1994.tb13270.x

Gerhardt, K. J. (1989). Characteristics of the fetal sheep sound environment. Semin. Perinatol. 13, 362-370.

Gerhardt, K. J., Abrams, R. M., and Oliver, C. C. (1990). Sound environment of the fetal sheep. Am. J. Obstet. Gynecol. 162, 282-287. doi: 10.1016/00029378(90)90866-6

Gordon, K. A., Wong, D. D., Valero, J., Jewell, S. F., Yoo, P., and Papsin, B. C. (2011). Use it or lose it? Lessons learned from the developing brains of children who are deaf and use cochlear implants to hear. Brain Topogr. 24, 204-219. doi: 10.1007/s10548-011-0181-2

Gourevitch, B., Edeline, J.-M., Occelli, F., and Eggermont, J. J. (2014). Is the din really harmless? Long-term effects of non-traumatic noise on the adult auditory system. Nat. Rev. Neurosci. 15, 483-491. doi: 10.1038/nrn3744
Granier-Deferre, C., Ribeiro, A., Jacquet, A. Y., and Bassereau, S. (2011). Nearterm fetuses process temporal features of speech. Dev. Sci. 14, 336-352. doi: $10.1111 / j .1467-7687.2010 .00978 . x$

Graven, S. N. (2000). Sound and the developing infant in the NICU: conclusions and recommendations for care. J. Perinatol. 20, S88-S93. doi: 10.1038/sj.jp.7200444

Graven, S. N., and Browne, J. V. (2008). Auditory development in the fetus and infant. Newborn Infant Nurs. Rev. 8, 187-193. doi: 10.1053/j.nainr.2008.10.010

Guinan, J. J. Jr. (2006). Olivocochlear efferents: anatomy, physiology, function, and the measurement of efferent effects in humans. Ear Hear. 27, 589-607. doi: 10.1097/01.aud.0000240507.83072.e7

Guiraud, J., Besle, J., Arnold, L., Boyle, P., Giard, M.-H., Bertrand, O., et al. (2007). Evidence of a tonotopic organization of the auditory cortex in cochlear implant users. J. Neurosci. 27, 7838-7846. doi: 10.1523/JNEUROSCI.0154-07.2007

Hall, J. W. 3rd. (2000). Development of the ear and hearing. J. Perinatol. 20, S12-S20. doi: $10.1038 /$ sj.jp. 7200439

Halwani, G. F., Loui, P., Ruber, T., and Schlaug, G. (2011). Effects of practice and experience on the arcuate fasciculus: comparing singers, instrumentalists, and non-musicians. Front. Psychol. 2:156. doi: 10.3389/fpsyg.2011.00156

Hammer, C. S., Farkas, G., and Maczuga, S. (2010). The language and literacy development of Head Start children: a study using the family and child experiences survey database. Lang. Speech Hear. Serv. Sch. 41, 70-83. doi: 10.1044/0161-1461(2009/08-0050)

Hart, B., and Risley, T. R. (2010). Meaningful Differences in the Everyday Experience of Young American Children. Baltimore, MD: P.H. Brookes.

Hasani, S., and Jafari, Z. (2013). Effect of infant prematurity on auditory brainstem response at preschool age. Iran. J. Otorhinolaryngol. 25, 107-114.

Hepper, P. G., and Shahidullah, B. S. (1994). Development of fetal hearing. Arch. Dis. Child. 71, F81-F87. doi: 10.1136/fn.71.2.F81

Hyde, K. L., Lerch, J., Norton, A., Forgeard, M., Winner, E., Evans, A. C., et al. (2009). Musical training shapes structural brain development. J. Neurosci. 29, 3019-3025. doi: 10.1523/JNEUROSCI.5118-08.2009

Hygge, S., Boman, E., and Enmarker, I. (2003). The effects of road traffic noise and meaningful irrelevant speech on different memory systems. Scand. J. Psychol. 44, 13-21. doi: 10.1111/1467-9450.00316

Ingersoll, E. W., and Thoman, E. B. (1994). The breathing bear: effects on respiration in premature infants. Physiol. Behav. 56, 855-859. doi: 10.1016/00319384(94)90315-8

Jardri, R., Pins, D., Houfflin-Debarge, V., Chaffiotte, C., Rocourt, N., Pruvo, J. P., et al. (2008). Fetal cortical activation to sound at 33 weeks of gestation: a functional MRI study. Neuroimage 42, 10-18. doi: 10.1016/j.neuroimage.2008.04.247

Jiang, Z. D., and Chen, C. (2014). Impaired neural conduction in the auditory brainstem of high-risk very preterm infants. Clin. Neurophysiol. 125, 1231-1237. doi: 10.1016/j.clinph.2013.11.012

Kandler, K., Clause, A., and Noh, J. (2009). Tonotopic reorganization of developing auditory brainstem circuits. Nat. Neurosci. 12, 711-717. doi: 10.1038/nn.2332

Keith, R. W. (1999). Clinical issues in central auditory processing disorders. Lang. Speech Hear. Serv. Sch. 30, 339-344. doi: 10.1044/0161-1461.3004.339

Kellam, B., and Bhatia, J. (2008). Sound spectral analysis in the intensive care nursery: measuring high-frequency sound. J. Pediatr. Nurs. 23, 317-323. doi: 10.1016/j.pedn.2007.09.009

Kent, W. D., Tan, A. K., Clarke, M. C., and Bardell, T. (2002). Excessive noise levels in the neonatal ICU: potential effects on auditory system development. J. Otolaryngol. 31, 355-360. doi: 10.2310/7070.2002.34358

Kisilevsky, B. S., Hains, S. M., Lee, K., Xie, X., Huang, H., Ye, H. H., et al. (2003). Effects of experience on fetal voice recognition. Psychol. Sci. 14, 220-224. doi: $10.1111 / 1467-9280.02435$

Kisilevsky, B. S., Pang, L., and Hains, S. M. (2000). Maturation of human fetal responses to airborne sound in low- and high-risk fetuses. Early Hum. Dev. 58, 179-195. doi: 10.1016/S0378-3782(00)00075-X

Krueger, C., and Garvan, C. (2014). Emergence and retention of learning in early fetal development. Infant Behav. Dev. 37, 162-173. doi: 10.1016/j.infbeh.2013.12.007

Krueger, C., Wall, S., Parker, L., and Nealis, R. (2005). Elevated sound levels within a busy NICU. Neonatal Netw. 24, 33-37. doi: 10.1891/0730-0832.24.6.33

Kujala, A., Huotilainen, M., Uther, M., Shtyrov, Y., Monto, S., Ilmoniemi, R. J., et al. (2003). Plastic cortical changes induced by learning to communicate with nonspeech sounds. Neuroreport 14, 1683-1687. doi: 10.1097/00001756-20030915000005 
Kujawa, S. G., and Liberman, M. C. (2006). Acceleration of age-related hearing loss by early noise exposure: evidence of a misspent youth. J. Neurosci. 26, 2115-2123. doi: 10.1523/JNEUROSCI.4985-05.2006

Lahav, A. (2014). Questionable sound exposure outside of the womb: frequency analysis of environmental noise in the neonatal intensive care unit. Acta Paediatr. doi: 10.1111/apa.12816. [Epub ahead of print].

Lecanuet, J. P., and Schaal, B. (1996). Fetal sensory competencies. Eur. J. Obstet. Gynecol. Reprod. Biol. 68, 1-23. doi: 10.1016/0301-2115(96)02509-2

Lee, G. Y., and Kisilevsky, B. S. (2014). Fetuses respond to father's voice but prefer mother's voice after birth. Dev. Psychobiol. 56, 1-11. doi: 10.1002/dev. 21084

Liu, W. F. (2012). Comparing sound measurements in the single-family room with open-unit design neonatal intensive care unit: the impact of equipment noise. J. Perinatol. 32, 368-373. doi: 10.1038/jp.2011.103

Livera, M. D., Priya, B., Ramesh, A., Suman Rao, P. N., Srilakshmi, V., Nagapoornima, M., et al. (2008). Spectral analysis of noise in the neonatal intensive care unit. Indian J. Pediatr. 75, 217-222. doi: 10.1007/s12098-008-0048-z

Maison, S. F., Usubuchi, H., and Liberman, M. C. (2013). Efferent feedback minimizes cochlear neuropathy from moderate noise exposure. J. Neurosci. 33, 5542-5552. doi: 10.1523/JNEUROSCI.5027-12.2013

Moore, J. K., and Linthicum, F. H. (2007). The human auditory system: a timeline of development. Int. J. Audiol. 46, 460-478. doi: 10.1080/14992020701383019

Moore, R. J., Vadeyar, S., Fulford, J., Tyler, D. J., Gribben, C., Baker, P. N., et al. (2001). Antenatal determination of fetal brain activity in response to an acoustic stimulus using functional magnetic resonance imaging. Hum. Brain Mapp. 12, 94-99. doi: 10.1002/1097-0193(200102)12:2<94::AID-HBM1006>3.0.CO;2-E

Moreno, S., Marques, C., Santos, A., Santos, M., Castro, S. L., and Besson, M. (2009). Musical training influences linguistic abilities in 8-year-old children: more evidence for brain plasticity. Cereb. Cortex.19, 712-723. doi: 10.1093/cercor/bhn 120

Morlet, T., Collet, L., Salle, B., and Morgon, A. (1993). Functional maturation of cochlear active mechanisms and of the medial olivocochlear system in humans. Acta Otolaryngol. 113, 271-277. doi: 10.3109/00016489309135808

Oliver, D. L., Izquierdo, M. A., and Malmierca, M. S. (2011). Persistent effects of early augmented acoustic environment on the auditory brainstem. Neuroscience 184, 75-87. doi: 10.1016/j.neuroscience.2011.04.001

Pantev, C., Oostenveld, R., Engelien, A., Ross, B., Roberts, L. E., and Hoke, M. (1998). Increased auditory cortical representation in musicians. Nature 392, 811-814. doi: $10.1038 / 33918$

Parbery-Clark, A., Anderson, S., Hittner, E., and Kraus, N. (2012). Musical experience offsets age-related delays in neural timing. Neurobiol. Aging 33, 1483.e1-1483.e4. doi: 10.1016/j.neurobiolaging.2011.12.015

Parbery-Clark, A., Skoe, E., and Kraus, N. (2009). Musical experience limits the degradative effects of background noise on the neural processing of sound. J. Neurosci. 29, 14100-14107. doi: 10.1523/JNEUROSCI.3256-09.2009

Partanen, E., Kujala, T., Näätänen, R., Liitola, A., Sambeth, A., and Huotilainen, M. (2013). Learning-induced neural plasticity of speech processing before birth. Proc. Natl. Acad. Sci. U.S.A. 110, 15145-15150. doi: 10.1073/pnas.1302159110

Pasman, J. W., Rotteveel, J. J., de Graaf, R., Maassen, B., and Visco, Y. M. (1996). The effects of early and late preterm birth on brainstem and middle-latency auditory evoked responses in children with normal neurodevelopment. J. Clin. Neurophysiol. 13, 234-241. doi: 10.1097/00004691-199605000-00007

Philbin, M. K., and Gray, L. (2002). Changing levels of quiet in an intensive care nursery. J. Perinatol. 22, 455-460. doi: 10.1038/sj.jp.7210756

Phillips-Silver, J., Aktipis, C. A., and Bryant, G. A. (2010). The ecology of entrainment: foundations of coordinated rhythmic movement. Music Percept. 28, 3-14. doi: $10.1525 / \mathrm{mp} .2010 .28 .1 .3$

Pujol, R., and Lavigne-Rebillard, M. (1992). Development of neurosensory structures in the human cochlea. Acta Otolaryngol. 112, 259-264.

Pujol, R., Lavigne-Rebillard, M., and Uziel, A. (1991). Development of the human cochlea. Acta Otolaryngol. Suppl. 482, 7-12. discussion: 3. doi: $10.3109 / 00016489109128023$

Querleu, D., Renard, X., Versyp, F., Paris-Delrue, L., and Crepin, G. (1988). Fetal hearing. Eur. J. Obstet. Gynecol. Reprod. Biol. 28, 191-212. doi: 10.1016/00282243(88)90030-5

Ramirez-Esparza, N., Garcia-Sierra, A., and Kuhl, P. K. (2014). Look who's talking: speech style and social context in language input to infants are linked to concurrent and future speech development. Dev. Sci. 17, 880-891. doi: $10.1111 /$ desc. 12172
Resendes, B. L., Williamson, R. E., and Morton, C. C. (2001). At the speed of sound: gene discovery in the auditory system. Am. J. Hum. Genet. 69, 923-935. doi: $10.1086 / 324122$

Roberts, J., Jurgens, J., and Burchinal, M. (2005). The role of home literacy practices in preschool children's language and emergent literacy skills. J. Speech Lang. Hear. Res. 48, 345-359. doi: 10.1044/1092-4388(2005/024)

Roopakala, M. S., Dayananda, G., Manjula, P., Konde, A. S., Acharya, P. T., Srinivasa, R., et al. (2011). A comparative study of brainstem auditory evoked potentials in preterm and full-term infants. Indian J. Physiol. Pharmacol. 55, 44-52.

Rowe, M. L., and Goldin-Meadow, S. (2009). Differences in early gesture explain SES disparities in child vocabulary size at school entry. Science 323, 951-953. doi: $10.1126 /$ science. 1167025

Salthouse, T. A., and Lichty, W. (1985). Tests of the neural noise hypothesis of age-related cognitive change. J. Gerontol. 40, 443-450. doi: 10.1093/geronj/ 40.4.443

Sanes, D. H., and Woolley, S. M. (2011). A behavioral framework to guide research on central auditory development and plasticity. Neuron 72, 912-929. doi: 10.1016/j.neuron.2011.12.005

Seki, S., and Eggermont, J. J. (2003). Changes in spontaneous firing rate and neural synchrony in cat primary auditory cortex after localized tone-induced hearing loss. Hear. Res. 180, 28-38. doi: 10.1016/S0378-5955(03)00074-1

Skoe, E., and Chandrasekaran, B. (2014). The layering of auditory experiences in driving experience-dependent subcortical plasticity. Hear. Res. 311, 36-48. doi: 10.1016/j.heares.2014.01.002

Skoe, E., Krizman, J., and Kraus, N. (2013). The impoverished brain: disparities in maternal education affect the neural response to sound. J. Neurosci. 33, 17221-17231. doi: 10.1523/JNEUROSCI.2102-13.2013

Smith, C. R., and Steinschneider, A. (1975). Differential effects of prenatal rhythmic stimulation on neonatal arousal states. Child Dev. 46, 574-578. doi: $10.2307 / 1128162$

Sohmer, H., Perez, R., Sichel, J. Y., Priner, R., and Freeman, S. (2001). The pathway enabling external sounds to reach and excite the fetal inner ear. Audiol. Neurootol. 6, 109-116. doi: 10.1159/000046817

Song, J. H., Skoe, E., Wong, P. C., and Kraus, N. (2008). Plasticity in the adult human auditory brainstem following short-term linguistic training. J. Cogn. Neurosci. 20, 1892-1902. doi: 10.1162/jocn.2008.20131

Starr, A., Amlie, R. N., Martin, W. H., and Sanders, S. (1977). Development of auditory function in newborn infants revealed by auditory brainstem potentials. Pediatrics 60, 831-839.

Strait, D. L., and Kraus, N. (2014). Biological impact of auditory expertise across the life span: musicians as a model of auditory learning. Hear. Res. 308, 109-121. doi: 10.1016/j.heares.2013.08.004

Strait, D. L., O’Connell, S., Parbery-Clark, A., and Kraus, N. (2014). Musicians' enhanced neural differentiation of speech sounds arises early in life: developmental evidence from ages 3 to 30. Cereb. Cortex 24, 2512-2521. doi: 10.1093/cercor/bht103

Strait, D. L., Parbery-Clark, A., Hittner, E., and Kraus, N. (2012). Musical training during early childhood enhances the neural encoding of speech in noise. Brain Lang. 123, 191-201. doi: 10.1016/j.bandl.2012.09.001

Szymczak, S. E., and Shellhaas, R. A. (2014). Impact of NICU design on environmental noise. J. Neonatal. Nurs. 20, 77-81. doi: 10.1016/j.jnn.2013.07.003

Talavage, T. M., Ledden, P. J., Benson, R. R., Rosen, B. R., and Melcher, J. R. (2000). Frequency-dependent responses exhibited by multiple regions in human auditory cortex. Hear. Res. 150, 225-244. doi: 10.1016/S0378-5955(00) 00203-3

Therien, J. M., Worwa, C. T., Mattia, F. R., and deRegnier, R. A. (2004). Altered pathways for auditory discrimination and recognition memory in preterm infants. Dev. Med. Child Neurol. 46, 816-824. doi: 10.1111/j.14698749.2004.tb00447.x

Tremblay, K., Kraus, N., McGee, T., Ponton, C., and Otis, B. (2001). Central auditory plasticity: changes in the N1-P2 complex after speech-sound training. Ear Hear. 22, 79-90. doi: 10.1097/00003446-200104000-00001

Ullal-Gupta, S., Vanden Bosch der Nederlanden, C. M., Tichko, P., Lahav, A., and Hannon, E. E. (2013). Linking prenatal experience to the emerging musical mind. Front. Syst. Neurosci. 7:48. doi: 10.3389/fnsys.2013.00048

Voegtline, K. M., Costigan, K. A., Pater, H. A., and DiPietro, J. A. (2013). Nearterm fetal response to maternal spoken voice. Infant Behav. Dev. 36, 526-533. doi: 10.1016/j.infbeh.2013.05.002 
Vohr, B. (2014). Speech and language outcomes of very preterm infants. Semin. Fetal Neonatal Med. 19, 78-83. doi: 10.1016/j.siny.2013.10.007

Walker, D., Grimwade, J., and Wood, C. (1971). Intrauterine noise: a component of the fetal environment. Am. J. Obstet. Gynecol. 109, 91-95.

White, R. D. (2011). Designing environments for developmental care. Clin. Perinatol. 38, 745-749. doi: 10.1016/j.clp.2011.08.012

White, R. D., Smith, J. A., and Shepley, M. M. (2013). Recommended standards for newborn ICU design, eighth edition. J. Perinatol. 33(Suppl. 1), S2-S16. doi: 10.1038/jp.2013.10

Williams, A. L., van Drongelen, W., and Lasky, R. E. (2007). Noise in contemporary neonatal intensive care. J. Acoust. Soc. Am. 121(Pt 1), 2681-2690. doi: $10.1121 / 1.2717500$

Yin, R., Wilkinson, A. R., Chen, C., Brosi, D. M., and Jiang, Z. D. (2008). No close correlation between brainstem auditory function and peripheral auditory threshold in preterm infants at term age. Clin. Neurophysiol. 119, 791-795. doi: 10.1016/j.clinph.2007.12.012

Zhang, L. I., Bao, S., and Merzenich, M. M. (2001). Persistent and specific influences of early acoustic environments on primary auditory cortex. Nat. Neurosci. 4, 1123-1130. doi: 10.1038/nn745

Zhang, L. I., Bao, S., and Merzenich, M. M. (2002). Disruption of primary auditory cortex by synchronous auditory inputs during a critical period. Proc. Natl. Acad. Sci. U.S.A. 99, 2309-2314. doi: 10.1073/pnas.261707398
Zhou, X., Panizzutti, R., de Villers-Sidani, E., Madeira, C., and Merzenich, M. M. (2011). Natural restoration of critical period plasticity in the juvenile and adult primary auditory cortex. J. Neurosci. 31, 5625-5634. doi: 10.1523/JNEUROSCI.6470-10.2011

Conflict of Interest Statement: The authors declare that the research was conducted in the absence of any commercial or financial relationships that could be construed as a potential conflict of interest.

Received: 25 September 2014; accepted: 08 November 2014; published online: 05 December 2014.

Citation: Lahav A and Skoe E (2014) An acoustic gap between the NICU and womb: a potential risk for compromised neuroplasticity of the auditory system in preterm infants. Front. Neurosci. 8:381. doi: 10.3389/fnins.2014.00381

This article was submitted to Auditory Cognitive Neuroscience, a section of the journal Frontiers in Neuroscience.

Copyright (C) 2014 Lahav and Skoe. This is an open-access article distributed under the terms of the Creative Commons Attribution License (CC BY). The use, distribution or reproduction in other forums is permitted, provided the original author(s) or licensor are credited and that the original publication in this journal is cited, in accordance with accepted academic practice. No use, distribution or reproduction is permitted which does not comply with these terms. 